DOI 10.37882/2223-2982.2021.03.09

\title{
СОЦИАЛЬНО-ПЕДАГОГИЧЕСКИЕ ПРОТИВОРЕЧИЯ ПРИ ВНЕДРЕНИИ СИМУЛЯЦИОННЫХ ТЕХНОЛОГИЙ В МЕДИЦИНСКОЕ ОБРАЗОВАНИЕ
}

\section{SOCIO-PEDAGOGICAL CONTRADICTIONS IN THE INTRODUCTION OF SIMULATION TECHNOLOGIES IN MEDICAL EDUCATION \\ L. Gatiyatullina \\ A. Gilfanova \\ A. Tazieva}

Summary: Background: training a qualified doctor is not possible without contact with real patients, but the patient's safety and wellbeing are a fundamental ethical problem in medical education, which has led to the rapid development of augmented reality technologies as an alternative to many aspects of medical training. However, along with the advantages of simulation training, there are still a number of unexplored ego gaps, both organizational, psychological, philosophical, moral, ethical and social.

The aim of the study is to analyze the advantages and problems of implementing simulation technologies in medical education.

Methods: the following methods are used in the course of research: theoretical - analysis and synthesis, analogy in combination with induction, comparison and generalization, deductive method.

Results: we have combined the advantages of implementing simulation technologies for all subjects of medical education; for the first time, we have outlined a number of socio-pedagogical contradictions in the context of the topic under study; we have identified aspects of medical training that cannot be replaced by simulation technologies.

Conclusion: to get closer to medical reality, you need to constantly stay in this environment throughout the entire course of training. The actualization of modern simulation technologies in the field of Medicine brings to the second plan the issues of moral planning, the issues of relationship between doctor and patient, which have always occupied a leading place in the history of medical science. Consequently, simulation technologies can become an obstacle to full-fledged training of a medical professional if they take out of school time the presence on clinical bases and standard practice in hospitals, which takes up more than $50 \%$ of the total training time of a medical student.

Keywords: simulation training, medical education, moral and ethical problems, socio-pedagogical contradictions.
Гатиятуллина Лилия Лукмановна

преподаватель, ассистент, Казанский государственный медицинский университет

lilijaluk@yandex.ru

Гильфанова Алина Ильшатовна

Казанский государственный медицинский университет ilgil16@mail.ru

Тазиева Алия Фархатовна

Казанский государственный медицинский университет tazieva.alila@mail.ru

Аннотация: Обоснование: подготовка квалифицированного врача невозможна без контакта с реальными пациентами, но безопасность больного и его благополучие составляют фундаментальную этическую проблему в медицинском образовании, что обусловило стремительное развитие технологий дополненной реальности, как альтернативы многим аспектам подготовки медика. Однако, наряду с преимуществами симуляционного обучения, остаётся целый ряд неосвещённых его пробелов, как организационных, так и психологических, философских, морально-этических и социальных.

Цель исследования: проанализировать преимущества и проблемы внедрения симуляционных технологий в медицинское образование.

Методы: в ходе исследования использованы следующие методы: теоретические - анализ и синтез, аналогия в сочетании с индукцией, сравнение и обобщение, дедуктивный метод.

Результаты: мы свели воедино преимущества внедрения симуляционных технологий для всех субъектов медицинского образования; впервые очертили круг ряд социально-педагогических противоречий в контексте исследуемой темы; обозначили те аспекты подготовки медика, которые невозможно заместить симуляционными технологиями.

Заключение: чтобы стать ближе к медицинской реальности необходимо постоянно находиться в этой среде на всём протяжении обучения. Актуализация современных симуляционных технологий в области медицины отодвигает на второй план вопросы морального плана, вопросы взаимоотношения врача и пациента, которые всегда занимали ведущее место в истории медицинской науки. Следовательно, симуляционные технологии могут стать препятствием к полноценной подготовке медика-профессионала в том случае, если они вытеснят из учебного времени нахождение на клинических базах и стандартную практику в стационарах, занимая более 50\% от всего времени подготовки студента-медика.

Ключевые слова: симуляционное обучение, медицинское образование, морально-этические проблемы, социально-педагогические противоречия.

этическую проблему в медицинском образовании, что обусловило стремительное развитие технологий дополненной реальности, как альтернативы многим аспектам подготовки медика.

При обучении «у постели больного» приоритетом все 
же является лечение пациента, а не обучение студента. В 2009 г. Всемирным альянсом за безопасность пациентов при поддержке ВОЗ было опубликовано «Руководство по обеспечению безопасности пациентов» [1], в котором отмечается, что образовательные учреждения должны создать безопасную и надежную образовательную среду для обучения клиническим умениям.

Медицинские ошибки, которые можно было бы предупредить, регистрируются более чем у 400000 случаев в США и занимают третье место в структуре смертности после сердечно-сосудистой патологии и онкологии, что обусловливает необходимость улучшения обучения и практического аспекта подготовки специалистов и непрерывного профессионального развития врачей [2]. Безопасность и качество оказания медицинской помощи определяется уровнем практического мастерства медицинских специалистов, их коммуникативными навыками, умением работать в команде, способностью контролировать лечебный процесс в стрессовой ситуации. Мастерство требует длительной, тщательной отработки четкого взаимодействия всех участников образовательного процесса. Одним из признаков современного медицинского образования стало стремительное внедрение виртуальных технологий и симуляционных методов обучения в подготовку будущих врачей [3]. Однако наряду с преимуществами симуляционного обучения, остаётся целый ряд неосвещённых его пробелов, как организационных, так и психологических, философских, морально-этических и социальных.

Цель данной работы - проанализировать преимущества и проблемы внедрения симуляционных технологий в медицинское образование.

\section{Методы}

В ходе исследования использованы следующие методы: теоретические - анализ и синтез, аналогия в сочетании с индукцией, сравнение и обобщение, дедуктивный метод.

\section{Основная часть}

Симуляционные технологии, бесспорно, обладают колоссальным значением для безопасного формирования практических навыков студентов-медиков. В таблице 1 мы свели воедино преимущества внедрения симуляционных технологий для всех субъектов медицинского образования.

Итак, мы, конечно, осознаём все преимущества дополнения традиционного медицинского образования симуляционными технологиями. Однако, симуляционное обучение все же не является панацеей и ни в коем случае не сможет полностью заменить обучение «у по- стели больного» - обе технологии в современном образовательном процессе должны органично дополнять друг друга. В метааналитическом обзоре, который был опубликован McGaghie с соавторами в 2011 г., однозначно показал, что симуляционное обучение должно лишь предшествовать клиническому и дополнять его - только тогда оно позволит тем, кто учится, достичь более высокого уровня клинической компетентности [4].

\section{Результаты и обсужление}

Несмотря на повсеместное описание преимуществ использования симуляционных технологий в практике обучения студента-медика, констатируем отсутствие целостного изучения не только перспектив, но и проблем использования симуляционных методов обучения, что предопределяет ряд социально-педагогических противоречий между:

- социокультурными преобразованиями в системе медицинского высшего профессионального образования, ее ориентированностью на европейский и мировые стандарты подготовки специалистов и медленным реагированием системы высшего медицинского образования на современные запросы научно-технического прогресса и рынка труда;

- социальной необходимостью использования модернизированного медицинского оборудования, вызванного научным прогрессом и обновлением стандартов образования, недостаточным внедрением медицинскими ВУЗами современных методов и возможностей широкого спектра средств веб-технологий (что связано с недостаточным финансированием со стороны государства);

- традиционными технологиями формирования профессиональной компетентности у будущих врачей к работе в сфере охраны здоровья и наличием в профессиональном инструментарии таких специалистов, соответствующих мотивов, системного восприятия профессиональной реальности, знаний, опыта применения веб-технологий нового поколения;

- насущной необходимостью формирования профессиональной компетентности будущих врачей средствами веб-технологий и отсутствием эффективной ресурсно-ориентированной технологии ее осуществления в учреждениях высшего медицинского образования (отсутствие адаптированных рабочих программ);

- реальными возможностями эффективного использования современных технологий симуляционного обучения в учебной и практической деятельности студентов-медиков и недостаточным уровнем обеспечения педагогических условий для приобретения соответствующих профессиональных знаний, умений, навыков, опыта и ценностей будущих врачей. 
Таблица 1.

Преимущества внедрения симуляционных технологий в медицинском образовании

\begin{tabular}{|c|c|}
\hline Субъекты медицинского образования & Содержание преимуществ симуляционного обучения для субъекта медицинского образования \\
\hline Государство & $\begin{array}{l}\text { Повышение качества медицинского образования; } \\
\text { Уменьшение врачебных ошибок, улучшение оказания медицинской помощи населению; } \\
\text { Увеличение качества и продолжительности жизни населения. }\end{array}$ \\
\hline $\begin{array}{l}\text { Работодатели (главные врачи, руко- } \\
\text { водители медицинских учреждений) }\end{array}$ & $\begin{array}{l}\text { Уменьшение числа профессиональных ошибок; } \\
\text { Снижение риска ответственности за действия своих сотрудников; } \\
\text { Повышение качества оказания медицинской помощи; } \\
\text { Повышение авторитета своей организации. }\end{array}$ \\
\hline Студент & $\begin{array}{l}\text { Повышение качества полученного образования, доступ к большому количеству разнообразных клинических си- } \\
\text { туаций, в том числе редких, повышение эффективности обучения; } \\
\text { Личностно-ориентированный подход в обучении; } \\
\text { Гибкость образования при компьютерном моделировании клинических сценариев; } \\
\text { Высокая адаптивность учебного материала; } \\
\text { Стимулирование активной когнитивной деятельности, развитие мышления, основанного на принципах доказа- } \\
\text { тельной медицины; } \\
\text { Развитие навыков использовать накопленные теоретические знания с точки зрения конкретного проблемного } \\
\text { задания (например, клинического случая); } \\
\text { Сокращение барьера между теоретическими знаниями и практическими навыками; } \\
\text { Способность контролировать собственный прогресс; } \\
\text { Повышение мотивации к обучению; } \\
\text { Снижение стресса во время первых самостоятельных манипуляциях; } \\
\text { Отработка действий при редких и таких, что угрожают жизни, патологиях; } \\
\text { Неограниченное количество повторов для отработок навыков; }\end{array}$ \\
\hline Врач & $\begin{array}{l}\text { Быстрое вхождение в профессию; } \\
\text { Возможность непрерывного профессионального развития с использованием симуляционных кейс-методик об- } \\
\text { учения (в частности компьютерного моделирования); } \\
\text { Соответствие требованиям работодателей и ожиданиям пациентов. }\end{array}$ \\
\hline Преподаватели & $\begin{array}{l}\text { Эффективное и высококачественное обучение профессиональных компетенций тех, кто учится. } \\
\text { Создание базы симуляционных сценариев, что облегчает повседневную деятельность преподавателя, дает воз- } \\
\text { можность продемонстрировать редкие и тяжелые клинические случаи; } \\
\text { Массовая аудитория (большое количество студентов могут заниматься с учебными материалами в синхронных } \\
\text { режимах; } \\
\text { Возможность использования многообразия педагогических технологий, методов, форм и ресурсов взаимодей- } \\
\text { ствия между всеми участниками учебного процесса; } \\
\text { Способность контролировать учебный процесс, развитие знаний и навыков студентов, способность отслеживать } \\
\text { их успеваемость; } \\
\text { Объективация и автоматическая система оценки знаний студентов; } \\
\text { Необходимость освоения современных образовательных технологии для улучшения учебного процесса. }\end{array}$ \\
\hline Пациент & $\begin{array}{l}\text { Опыт в симуляционной среде не несет риска для пациента, пациент в конечном итоге получает более качествен- } \\
\text { ную медицинскую помощь, улучшается качество жизни больных. }\end{array}$ \\
\hline
\end{tabular}

Помимо вышесказанного, важно дополнить, что совет по аккредитации медицинского образования (ACGME) предлагает на рассмотрение 6 ключевых отраслей клинической компетенции студента:

1. уход за пациентом;

2. медицинские знания;

3. практико-ориентированное обучение и совершенствование;

4. межличностные и коммуникативные навыки;

5. профессионализм;

6. системность, базирующаяся на практике [5].
По нашему мнению, симуляционное образование помогает формированию только третьей и шестой компетенции из данного списка, так как непосредственное коммуникативное взаимодействие с реальным пациентом - это тот навык, который невозможно «симулировать».

В связи с этим, мы считаем, что существует ряд проблем в данной сфере:

1. Медицинское образование может перейти из плоскости реальности в виртуальное простран- 
ство большей своей частью, что обусловлено не только стремительным развитием внедрения технологий дополненной реальности в обучение, но и затянувшейся пандемией COVID-2019, которая наносит непоправимый урон образовательному процессу студентов медицинских университетов. Глобальность проблемы дистанционного образования тяжело переоценить, ведь многие века в медицинском образовании ключевым фактором в обучении был принцип «насмотренности», суть которого ясна всем субъектам с высшим медицинским образованием.

2. Интрапсихическое умение эмпатично «прочувствовать» пациента и его отношение к болезни это тот навык, который может быть приобретён только после многократного общения с реальным пациентом.

3. Комплаентность, то есть приверженность пациента к лечению - это незаменимый атрибут любого лечебного процесса, достижение которого требует целого комплекса отработанных коммуникативных и психологических стратегий медика.

4. Полиморбидность или коморбидность ряда заболеваний у одного пациента в реальной клинической практике может поставить в тупик студента, который изучал на симуляторах изолированные патологии органов или систем органов.

5. Помимо этого, существует колоссальное количество ситуаций, с которыми студент встречается только на клинических базах и которые невозможно смоделировать, предугадать и подготовиться к ним в «искусственных» условиях безопасной «комнаты симуляционных тренажёров» [6].

Столкнуться с медицинской реальностью, принять за одну рабочую смену десяток эмоционально лабильных пациентов, которые изначально скептически относятся к молодому специалисту; встретиться лицом к лицу с тяжёлыми онкологическими пациентами и их сформировавшимися взглядами на жизнь и лечение; принять ночью на приёмном покое практически несовместимую с жизнью политравму и увидеть 8-часовую непрерывную работу команды хирургов из разных отделений, которые буквально по кусочкам собирают пациента; присутствовать в гнойной перевязочной, привыкнуть к её запахам и уметь работать с реальными гноящимися ранами, ожогами $70 \%$ площади тела; уметь объяснять родителям ребёнка, что он больше никогда не сможет ходить или выйти из операционной и оповестить родных о смерти пациента - это всё то, что невозможно «симулировать» на тренажёрах. Чтобы стать ближе к медицинской реальности необходимо постоянно находиться в этой среде на всём протяжении обучения. Пусть для начала и не в качестве активного её участника, а лишь как незримая тень того врача/преподавателя, к которому студент прикреплён на соответствующей клинической базе.
Стремление к инновациям в научно-образовательной деятельности лишь тогда оправдано и эффективно, когда возникают новые философско-антропологические и научно-педагогические основания. Упрощение проблемы с приоритетом маргинальных элементов обучения неизбежно приведет к неэффективным решениям. Современные студенты и так большое количество времени проводят в виртуальной реальности и находятся в Интернете зачастую большую часть свободного времени, поэтому тотальная виртуализация обучения при своей неумеренности может иметь не только положительные последствия, а и отрицательные.

Мотив использования симуляционного обучения на сегодняшний день рассматривается только с позиций социального заказа, игнорируются особенности обучающегося, обучающего, философско-этические особенности предмета обучения, которым является живой человек.

Кроме того, игнорируется тот, кто учит - преподаватель, а на первое место ставится симулятор, который обучает и компьютеризированная система, которая выдаёт оценивание работы студента. Важно сформировать такую систему решений, где преподаватель должен сохранить ведущее место в системе подготовки врачей.

Актуализация современных симуляционных технологий в области медицины отодвигает на второй план вопросы морального плана, вопросы взаимоотношения врача и пациента, вопросы «живого» лечения (иногда лечения «словом»), которые всегда занимали ведущее место в истории медицинской науки и практик.

Следовательно, симуляционные технологии могут стать препятствием к полноценной подготовке медикапрофессионала в том случае, если они станут вытеснять из учебного времени нахождение на клинических базах и стандартную практику в стационарах, занимая более 50\% от всей подготовки студента-медика.

\section{Зак^ючение}

Использование симуляционных методов обучения не заменяет пациента. Моделирование клинических ситуаций в условиях, приближенных к реальным, позволяет обучать студентов и врачей, повышая уровень безопасности для пациентов. Для всех субъектов медицинского образования и оказания медицинской помощи населению в данной работе проанализированы возможные преимущества внедрения симуляционного обучения.

Перспективы дальнейших исследований могут заключаться в комплексной оценке влияния симуляционного обучения на всех субъектов медицинского обра- 
зования и оказания медицинской помощи населению, в проведении многоуровневых педагогических экспериментов относительно влияния симуляционных методов обучения на качество образования, знания и практические навыки для выбора наиболее эффективного вида комбинации традиционного и инновационного лечения.

Итак, несмотря на очевидные преимущества имитационных технологий, существует ряд причин, которые препятствуют их широкому распространению: ряд морально-этических проблем, нивелирование коммуникативно-психологического аспекта обучения медиков, снижение значимости преподавателя, как главного источника информации, высокая стоимость учебной техники, отсутствие общепринятых утвержденных методик, дефицит преподавательских кадров, владеющих приемами симуляционного обучения. Поэтому перед нами стоит важная задача преодоления этих барьеров для эф- фективного и разумного внедрения в образовательный процесс современных учебных технологий в виде центров симуляционных технологий на базе ВУЗов и клиник.

Современное развитие медицинской науки и практики предопределяет необходимость вносить коррективы в подготовку и повышение квалификации медицинских работников с приближением их образования к международным стандартам. Именно поэтому качество образования в высших учебных заведениях необходимо улучшить путем эффективной организации учебного процесса, с помощью внедрения передовых научных разработок в практику преподавания, обеспечение высокого профессионализма преподавателей, создание современной учебно-методической базы, что не обязательно должно достигаться лишь путём активного внедрения симуляционных технологий.

\section{ЛИТЕРАТУРА}

1. Резолюция WHA72.6. [Электронный доступ]. URL: https://www.who.int/ru/news-room/fact-sheets/detail/patient-safety (дата 0бращения 22.01.2021).

2. Krishnan D.G., Keloth A.V., Ubedulla S. Pros and cons of simulation in medical education: a review // Education. 2017. T. 3. №. 6. P. 84-87.

3. Willi B., Piquette D., Mema B. Mastery in Simulation in Critical Care before Transitioning to Practice. Are There Drawbacks? //ATS Scholar. 2020. T.1. №.3. P. 205-210.

4. McGaghie W.C. et al. Does simulation-based medical education with deliberate practice yield better results than traditional clinical education? A meta-analytic comparative review of the evidence // Academic medicine: journal of the Association of American Medical Colleges. 2011. T. 86. №.6. 706 p.

5. Warm E.J. et al. The ambulatory long-block: an accreditation council for graduate medical education (ACGME) educational innovations project (EIP) // Journal of general internal medicine. 2008. T.23. №. 7. P. 921-926.

6. Sakakushev B.E. et al. Striving for better medical education: the simulation approach // Folia medica. 2017. T.59. №. 2. P. 123-131.

( Гатиятуллина Лилия Лукмановна (lilijaluk@yandex.ru), Гильфанова Алина Ильшатовна (ilgil16@mail.ru), Тазиева Алия Фархатовна (tazieva.alila@mail.ru).

Журнал «Современная наука: актуальные проблемы теории и практики» 